\title{
Commentary: What's the point?
}

\author{
Charles B. Huddleston, MD
}

\author{
From the Department of Surgery, St Louis University School of Medicine, St Louis, Mo. \\ Disclosures: Author has nothing to disclose with regard to commercial support. \\ Received for publication March 9, 2019; accepted for publication March 11, 2019. \\ Address for reprints: Charles B. Huddleston, MD, 1465 S. Grand Blvd, St Louis, MO 63104 (E-mail: Charles. \\ huddleston@health.slu.edu). \\ J Thorac Cardiovasc Surg 2019;157:e411-2 \\ $0022-5223 / \$ 36.00$ \\ Copyright (c) 2019 by The American Association for Thoracic Surgery \\ https://doi.org/10.1016/j.jtcvs.2019.03.024
}

Pulmonary thromboendarterectomy is a well-established procedure for chronic thromboembolic pulmonary hypertension (CTEPH) with generally good results. ${ }^{1}$ It is remarkable how successful this procedure is, given the gravity of the condition of these patients preoperatively, the enormity of the operation required, and the complexity of the postoperative care. In this issue of the Journal, investigators from Toronto describe a case report of a 3year-old who was successfully treated with surgery for CTEPH. ${ }^{2}$ Why do case reports get published and what is the point of this one? We publish case reports because they provide an avenue for the presentation of an unusual, rare diagnosis or treatment that would never reach the point of a case series. Hopefully, the authors have thoughtfully delved into the nuances of the pathophysiology to provide insights of all aspects of the case. Readers can thereby profit from the single published experience when they encounter a similar case. How else might we learn of a neck fracture resulting from the explosion of an ecigarette? ${ }^{3}$

So, what is the point of the case report you have just read before reading this insightful editorial comment? First, we should compliment the investigators at Toronto's Hospital for Sick Children on their expertise in the diagnosis and management of a 3-year-old girl with a history of neuroblastoma. This may be the smallest and youngest child to undergo and survive this procedure. So, yes, it is possible to perform pulmonary endarterectomy on a small child. Perhaps the bigger question is why did this patient develop this potential devastating complication of a Denver shunt? Is this related to having a chronic indwelling catheter in the venous system? Literally thousands of children have portacaths or Broviac catheters (Bard, Salt Lake City, Utah) in place as part of their treatment for a variety of illnesses. Many children also have transvenous pacemaker leads in place. It is common to see clots on these catheters and leads during routine echocardiography and at the time of open surgery. However, investigations into the presence of pulmonary emboli are rarely performed. Perhaps we are afraid of what we might find! Most indwelling venous

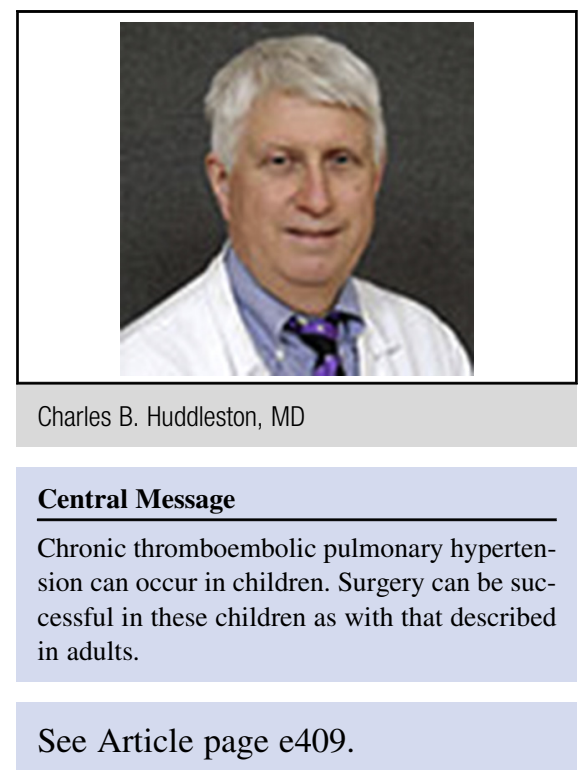

catheters are there for the infusion of a variety of drugs or total parenteral nutrition. The peritoneal-venous shunt infuses ascites or, in this case, chylous ascites. This fluid contains a variety of proteins, all of which circulate normally. Clotting abnormalities have been reported in conjunction with the shunt, usually disseminated intravascular coagulation. It is not unusual for these shunts to occlude from low flow or perhaps as a result of the presence of clotting factors in ascites. The catheters are relatively large bore compared with the typical indwelling venous catheter. The smallest commercially available is 11.5F. This has an external diameter of $4.5 \mathrm{~mm}$, which would take up a considerable amount of space within the subclavian vein, thus putting it at risk for thrombus formation and presumably a potential site for the propagation of pulmonary emboli.

Thrombi could also form on the catheter itself and result in pulmonary emboli. Should we screen all patients for thrombus formation on indwelling venous catheters? Clinical experience would dictate otherwise. The incidence of thrombus formation on catheters left in place for greater than 2 weeks is $10 \%$ to $15 \% .^{4,5}$ In no case was the thrombus itself a cause of complications, and none had pulmonary emboli clinically. Thus, screening with echocardiography or ultrasound would not appear to be cost-effective.

So, what have I learned from reading this case report? First, a patient with a chronic indwelling venous catheter who demonstrates evidence of pulmonary hypertension on 
echocardiography should be screened further for CTEPH. Second, pulmonary thromboendarterectomy can be successfully performed even in small children (at least in Toronto).

\section{References}

1. Mandani MM, Auger WR, Pretorius V, Sakakibara N, Kerr KM, Kim NH, et al. Pulmonary endarterectomy: recent changes in a single institution's experience of more than 2700 patients. Ann Thorac Surg. 2012;94:97-103.
2. Humpl T, Honjo O, Temple M, de Perrot M. Pulmonary endarterectomy in a toddler with chronic thromboembolic pulmonary hypertension after Denver shunt. J Thorac Cardiovasc Surg. 2019;157:e409-10.

3. Norii T, Plate A. Electronic cigarette explosion resulting in a $\mathrm{C} 1$ and $\mathrm{C} 2$ fracture: a case report. J Emerg Med. 2017;52:86-8.

4. Haddad H, Lee KS, Higgins A, McMilland D, Price V, El-Naggar W. Routine surveillance ultrasounds for the management of central venous catheters in neonates. J Pediatr. 2014;164:118-22.

5. Mehta S, Connors AF, Danish EH, Grisone E. Incidence of thrombosis during central venous catheterization of newborns: a prospective study. J Pediatr Surg. 1992; 27:18-22. 